\title{
Mortality from suicide among the residents of the capital of the Russian empire after the fall of serfdom (I873-I897)
}

\begin{abstract}
The article discusses the sources for the study of mortality dynamics among the population of the capital of the Russian Empire from suicide in the period after the abolition of serfdom up to the end of the XIX century. The characteristics of the study of suicidal manifestations in Saint-Petersburg is given suicide statistics in SaintPetersburg according to the Moscow Mayor and the Russian Ministry of Internal Affairs is compared.
\end{abstract}

Keywords: reforms, suicide, underreporting of violent deaths, Saint Petersburg city administration, ministry of internal affairs
Volume 2 Issue 2 - 2018

Bogdanov Sergei, Gudova Yulia

University Belgorod State National Research University, Russia

Correspondence: Bogdanov Sergei, University Belgorod State National Research University, Pobedy St., Belgorod, 3080I5, Russia, Email dr.bogdanov_sv@mail.ru

Received: January II, 20I8 | Published: March 16, 2018

\section{Introduction}

The phenomenon of suicide in the Russian society of the XIX century has been studied by sociologists, philosophers, doctors, lawyers and teachers. However, among the numerous researchers of this phenomenon, historians are quite a rare matter. Meanwhile, the sustainable reproduction of suicides is one of the indicators, denoting the presence of systemic deformations in the diversity of social relations, especially in terms of increased mortality. Deformations become particularly acute in the periods of large-scale transformations, which cause the increase of suicidal activity of the population. Therefore, to recreate a complete picture of certain time periods, it is crucial to consider the totality of phenomenon, processes, trends, both creative and destructive. One of these destructive phenomena is the suicide.

\section{Research method}

The specific feature of the proposed research is that on the basis of various statistical sources, mortality rates from suicide among the population over 16 years in various parts of the capital of the Russian Empire-Saint-Petersburg-and their dynamics over the years 1873 1897 were first-born. The main causes of the undercount of the facts of violent deaths in the capital of the Russian Empire in the post-reform decade have been also identified. Also, the State capital is not chosen by chance. The choice was predetermined by two factors. First, the virtual absence of contemporary historical-demographic research of suicides in St. Petersburg in the second half of the nineteenth century. Second, the need to identify the complexity of factors, which have predetermined the fluctuations in the level of suicidal activity of the population of the largest city of Russia at that period. A significant number of specialists admitted the influence of alcohol abuse on the increased suicidal activity of the population, especially in terms of social transformations. However, the problem of identifying the relationship between alcohol and suicide has remained insufficiently studied. V.O. Mikhnevich, a well-known publicist, when examining the influence of alcohol abuse on the growth of social deviations in his thorough work "The Ulcers of Petersburg", admitted: "There have been very few attempts for an accurate, well-founded study of this phenomenon at a large scale, and we do not have enough accurate information on that phenomenon". ${ }^{1}$

Meanwhile, a significant amount of indirect information allows us to state that the growth of alcohol consumption by the population of the capital of the Russian Empire during the second half of the 19 th century had its effect on the increased number of suicides. ${ }^{2}$ One of the influential experts on fighting with alcohol abuse at that time, noted in his thesis: "At the moment alcohol abuse is one of the most active factors of population reduction. Like the epidemic, it produces huge devastation of the social organism, increases the number of neurotics, epileptics, gives a huge number of mentally ill criminals, and contributes to degeneration and extinction of children, not to mention the fact that it is extremely fatal to the health of the alcoholics themselves. It hurts the well-being of their families, threatens to transform such persons into real mental patients, dangerous to others and often ending life either prematurely, or committing suicide. ${ }^{2}$ At the same time, turning alcohol abuse exclusively into the lot of the lumpenized population stratum is a serious simplification of the real situation in the Russian society immediately after the fall of serfdom. This way, the doctor F.F. Herman, studying the death rate "from drinking" of St. Petersburg residents in the first post-reform years, found that the majority of the deceased suddenly died from excessive consumption of alcohol were not from the lower classes of society, but mostly small officials with a certain allowance or pension. ${ }^{3}$

In the works of some authors of the second half of the XIX century, there are facts of involving children and adolescents in the consumption of alcohol at an early age. For instance, N.I. Grigoriev, a well-known expert on the problems of alcoholism writes the following: "The custom of drinking children with alcoholic beverages is a harmful custom which is extremely developed in St. Petersburg. In families with a certain income, children very often get used to drinking beer and wine, receiving them from their parents during breakfast, lunch or dinner; in other cases, this habit is established in early childhood, when the child is given wine for strengthening or for a good sleep. The habit of drinking light wines or beer inherited from childhood rarely 
remains the same. More often it turns into the need for stronger drinks, and hence there is one step to alcohol abuse left. It hardly needs saying that among the capital students, especially among the natives of St. Petersburg, a rare party is accompanied with no drink. Among ordinary people, such as workers and those involved in physical labor, children are often deliberately accustomed to vodka, since it is treated as a useful drink a working person cannot live without Vodka is given even to nursing infants, so that they are stronger and calmer. ${ }^{4} \mathrm{~A}$ large growth of alcohol abuse among the capital population of the Russian Empire was reflected in the work "The Most Recent Reports of the St. Petersburg Governor's Office and the Police." Thus, according to these documents, the number of detainees in the state of intoxication for sobering up at 13 police stations was only 393754 people between 1885 and 1894 . Almost every year there was an increase in this figure: in 1885-31567 detainees, in 1886-38166, in 1887-39048, in 1888-39281, in 1889-36770, in 1890-36589, in $1891-42546$, in 1892-41227, in 1893-40360, in 1894-48200 (The most recent reports ..., 1887-1896). In general, the constant increase in the consumption of alcohol by the residents of St. Petersburg led to an increase in the number of citizens who were diagnosed with alcohol abuse by capital doctors, as well as those who were referred to as mentally ill people. These people were at risk, with suicides being very frequently recorded.

\section{The main part}

We can identify several periods in the study of the suicide phenomenon among the population of the Russian Empire, each characterized by specific approaches, not only due to the positions of the authors, who have studied this issue, but to the influence of the dominant state ideology. The first period: the beginning-the first half of XIX century. The number of scientific investigations, devoted to suicides in St. Petersburg, was insignificant. Undisputed interest among contemporaries and later researchers called the report of academician ${ }^{3}$,"Survey on numbers of homicides and suicides in Russia in the years 1819-1820", which was published in 1823. Separate data on suicides in the 30-40-ies of the XIX century were published in the various descriptions of the capital, essays "on people's morality", intended for the wide-scale reading public. ${ }^{5,6}$ However, a serious analysis of suicide in these works was absent. The period of public backlash initiated by Nicholas I, was marked, above all, by the tightening of censorship attack on any printed materials. The theme of violent mortality in Russia, although was not prohibited at all, was still in the list of junk. This circumstance didn't contribute to the deployment of serious research on this issue. The exception, perhaps, was the work by K.S. Veselovsky "Experiences of moral statistics of Russia", which the reading public was able to see in $1847 .^{7}$

In this study, the problem of underreporting by the police of violent death in the country was first denoted. The fact that the book was printed in the printing house of the Ministry of Internal Affairs is very revealing in terms of the recognition by the Office of the seriousness of the problems identified. The second period: the second half of XIX-early XX centuries. It was a natural consequence of the general liberalization in the country after the abolition of serfdom that the social interest for everyday life, which was much more complex, and manifested not only in creative, but also in destructive phenomenacrime, suicide, alcoholism, etc. The impossibility of further use of the surface approach to the study of suicide in Russia, typical for the vast majority of publications in the preceding decades became obvious.
In the first half of the 1860 s the reading public had an opportunity to see the scientific research that is saturated with statistics, and presents sociological and psychological reasons for suicide. The most notable were the works. ${ }^{8,9}$ The most interesting works, in which the authors studied the dynamics of suicides in St. Petersburg, were researchworks by. ${ }^{10-14}$

The beginning of the XX century was marked by the increased attention of domestic experts to the problem of suicides. This was due to outbreaks of suicidal activity among pupils of educational institutions of the Russian Empire (Suicides, attempted murders..., 1906-1916; $;{ }^{15}$ the increase in the number of suicides in the army, including the officer corps (Voenno-statisticheskij 1911-1913). The scientific community continued to search for answers to many questions related to the phenomenology of suicide ${ }^{16}$ social conditions and factors of its reproduction. ${ }^{17,18}$ Special collections of articles, numerous newspaper and magazine publications were devoted to various aspects of suicides in St. Petersburg-Petrograd (Suicide in S.Petersburg..., 1913). Of course, this period was the most fruitful in terms of the emergence of numerous and diverse works, devoted to suicides in the Russian society. ${ }^{19-22}$

The third period is 1917-1987. During this period, the 1920s are out of the rank. Thanks to the efforts of M.N. Garnet, in the structure of the Central statistical office (CSO) of the USSR the Department of moral statistics was formed, that took suicide into account, among other manifestations of antisocial behavior. Since 1922, in the Soviet Russia, the registration of suicides in the special statistical sheets began. They were quite extensive and informative. ${ }^{23,24}$ In this decade a large number of scientific papers on suicides in the Soviet Union appeared. However, an appeal to the recent past of this social pathology in Russia became uncomfortable for ideological reasons: the level of suicides in the Soviet Russia was higher than in the Russian Empire. In 1930-70ies, in the USSR the theme of suicide was closed not only for society as a whole, but also for the scientific community. It was believed that the normal Soviet person is not capable of suicide..$^{25,26}$ During this period the problem of suicide has been studied only in the medicalbiological aspect. Publication statistics of suicides for the wide public in the USSR resumed only in 1988. The fourth period starts from the beginning of liberal reforms in the country and continues nowadays. Unfavorable demographic situation in the country has seriously actualized the problem of mortality from suicide. ${ }^{27-30}$ As a result, from 1993 to 2011, INION (Institute of Scientific Information on Social Sciences of the Russian Academy of Sciences RAN) reported 1,089 publications in this or that way, dealing with the problems of suicide. However, in modern Russian studies there are still very few research works, specifically focused on suicide in Russia in the second half of the nineteenth century. ${ }^{31,32}$

Official statistical data on number of suicides in St.-Petersburg are presented in two groups of sources, published by various departments: the Central Statistical Committee of the Ministry of Internal Affairs (further-CSK MIA) and the St. Petersburg City administration. ${ }^{33,34}$ In 1897, the edition of CSK MIA-the Annals "Died violently and suddenly in the Russian Empire in the years 1888-1893" was printed out (Annals of Central..., 1897). In comparison with the previous two statistical collections, dealing with violent and sudden deaths, this publication contained data for the years of 1885-1893 in all provinces and regions of the Russian Empire, except for the areas of the Don Cossacks, the Kara, the Tersk and the Caspian, Zaqatala and the Black 
sea districts. The "Annals" had another feature-it has first compiled statistics on violent and sudden deaths in ten major cities of European Russia during the period from 1870 to $1893.35,36$ The second group of sources-reports of the Saint Petersburg Mayor which has a rather detailed coverage of the various aspects of life in the capital of the Russian Empire. Data on suicides were published in the annexes to the report titled "Statistical table about the different incidents in St. Petersburg for ... year". Titles of reports from 1873 to 1893 were repeatedly changed: Humbly Report of the St. Petersburg Mayor; from 1894 to $1896-$ A review of the activities of the St. Petersburg municipal administration and the Metropolitan police; from 1897-The app to humbly report on the activities of the St. Petersburg Mayor (Humbly Report..., 1873-1893; A review of the activities..., 18941896).

Also a valuable source for statistics of suicides in the country's largest city is the "Statistical yearbook of St. Petersburg", which was initiated by the Head of the statistical Department at the St. Petersburg city administration Yu. E. Yanson. The first issue was published in 1882. Mapping the information of CSK MIA and St. Petersburg Mayor reveals a discrepancy of indicators, presented in the various documents. So, according to the calculations of CSK MIA, 18701893. (Data on number of suicides in Ministry reports for 1875, are missing) 2869 people died from the suicide in the capital of the state (Annals of Central..., 1897). At the same time, under humbly reports of the St. Petersburg Mayor during the 1873-1893. (Without 1880 and 1881-the report were not prepared), the number of suicides in the city is significantly different -2505 cases. Thus, in the Internal Ministry reports the number of deaths from suicide in St. Petersburg is 364 more than in the reports of the city Mayor. Apparently, these statistical differences are attributable to different timing of reception of information about the number of suicides to the Departments mentioned. This in turn led to the statistical discrepancies. However, considering the steady increase of the Metropolitan population, which has passed the one million mark by the end of the nineteenth century; this difference had no significant effect on calculations of the mortality rate from suicide. Dynamics of completed suicides in St.-Petersburg in 1873-1897 is presented in table 1 (Humbly reports..., 1873-1893; The app to Humbly report ..., 1897; Statistic annual..., 1889).

Table I The number of suicides in St. Petersburg (1873-1897)

\begin{tabular}{llll}
\hline Year & $\begin{array}{l}\text { Number of } \\
\text { suicides }\end{array}$ & $\begin{array}{l}\text { in\% to previous } \\
\text { year }\end{array}$ & in\% to I873 \\
\hline 1873 & 91 & - & - \\
1874 & 71 & 78 & 78 \\
1875 & 104 & 146.4 & 114.2 \\
1876 & 93 & 89.4 & 102.1 \\
1877 & 82 & 88.1 & 90.1 \\
1878 & 100 & 121.9 & 109.8 \\
1879 & 82 & 82 & 90.1 \\
1880 & 91 & 110.9 & 100 \\
1881 & 120 & 131.8 & 131.8 \\
1882 & 137 & 114.1 & 150.5 \\
1883 & 106 & 77.3 & 116.4 \\
\hline
\end{tabular}

Table Continued.....

\begin{tabular}{llll}
\hline Year & $\begin{array}{l}\text { Number of } \\
\text { suicides }\end{array}$ & $\begin{array}{l}\text { in\% to previous } \\
\text { year }\end{array}$ & in\% to I873 \\
\hline 1884 & 114 & 107.5 & 125.2 \\
1885 & 136 & 119.2 & 149.4 \\
1886 & 190 & 139.7 & 208.7 \\
1887 & 114 & 60.1 & 125.2 \\
1888 & 129 & 113.1 & 141.7 \\
1889 & 131 & 101.5 & 143.9 \\
1890 & 147 & 112.2 & 161.5 \\
1891 & 180 & 122.4 & 197.8 \\
1892 & 175 & 97.2 & 192.3 \\
1893 & 186 & 106.2 & 204.3 \\
1894 & 117 & 62.9 & 128.5 \\
1895 & 153 & 130.7 & 168.1 \\
1896 & 127 & 83 & 139.5 \\
1897 & 132 & 103.9 & 145 \\
\hline
\end{tabular}

\section{Conclusion}

Thus, during the last quarter of the XIX century in St. Petersburg there has been an increase in the number of completed suicides. The number of suicides has increased unevenly, but overall, by the end of the 1890s in comparison with the beginning of the 1870s the annual number of residents died from suicide in St. Petersburg has increased almost twice. Since the 1870-ies in the Russian capital the average annual number of completed suicides was on the increase. In 1873 1877 it accounted for 88.2 people, in $1878-1882$ it was 106.2 people, in 1883-1887-132 people; in 1888-1892 it was 152 people. Only in 1893-1897 this index had a downward trend, relative to the previous period, of 143 people.

\section{Insights}

During the period of 1873-1897, the years of ups and downs in recorded suicides were observed. However, any patterns in their alternation are not revealed. A kind of boundary, from which the number of suicides in the capital of the Russian state became evident, was the late 1870 - early 1880 -ies. Apparently, this was due to the intensification of law enforcement and bureaucracy which caused serious aggravation of the socio-political situation in the country, the change of leadership of the Ministry of Internal Affairs, the coming to power of a new Russian Tsar Alexander III, an outspoken supporter of strict government discipline and order. These circumstances contributed to the tightening of registration discipline of various incidents, including suicides.

\section{Acknowledgement}

None.

\section{Conflict of interest}

The authors declare that they have no conflict of interest. 


\section{References}

1. Mikhnevich V. Ulcers of St. Petersburg. The experience of historical and statistical study of the morality of the capital's population in 3 volumes. T.3. St. Petersburg; 1886.

2. Kolpakov MN. To the question of alcoholism in St. Petersburg and the measures of social struggle against it in connection with the establishment of special clinics for alcoholics: dis. to a doctorate in medicine. St. Petersburg; 1896.

3. Herman FF. About Drunkenness in Russia // Archive of Forensic Medicine and Public Hygiene; 1868.

4. Grigoryev NI. Alcoholism and crimes in St Petersburg: based on materials from the St Petersburg Mountains. Hospital and Archives of the St Petersburg District Court. SPb; 1900.

5. Pushkarev I. Description of St. Petersburg and the County towns of St Petersburg province. Saint-Petersburg; 1839.

6. Antropov RL. Why the youth commits suicide: a socio-writer, essays of sexual and other psychoses posteriors. Period. Saint-Petersburg; 1911.

7. Veselovsky KS. Experiences of moral statistics in Russia. SaintPetersburg; 1847.

8. Likhachev AV. Suicide in Western Europe and European Russia: a Comparative statistical study. Saint-Petersburg; 1882.

9. Ponomarev N. Suicide in Western Europe and in Russia in connection with the development of insanity: stat. issled. Saint-Petersburg; 1880.

10. Hubner J. Suicide in St. Petersburg. Saint-Petersburg; 1909.

11. Zagorsky P. Mortality in P. S. B. for 1878, St. Petersburg; 1880.

12. Lipsky AA. The Suicide of children in St. Petersburg. Saint-Petersburg; 1887.

13. Belyakov SA. Of suicide, accidents, and psychiatric institutions: report of St. Petersburg, about-Woo psychiatrists in meeting, on 14 November 1892 in Saint Petersburg; 1893.

14. Terekhovko FK. On the issue of suicide in St. Petersburg for 20 years (1881-1900): dis. on a step. Dr. med. Gatchina; 1898.

15. Horoshko VK. The Suicide of children. Moscow; 1909.

16. Lebedev N. Suicide as a socio-ethics evil. Moscow; 1913

17. Suicide in St. Petersburg 1911-1912: causes and measures to counter them. Dr. Prozorov. Saint-Petersburg; 1913.

18. Prozorov LA. The Suicide of the mentally ill in hospitals. Modern psychiatry; 1915; $3 \mathrm{p}$.
19. The Bashutsk AP. Panorama of St. Petersburg. Part 2. Saint-Petersburg; 1834.

20. Bernatsky VA. Suicide among pupils of military educational institutions Saint-Petersburg; 1911.

21. Bronze AA. Suicide. Saint-Petersburg; 1912.

22. Belacel PF. Suicide from ancient times to the present day: its, essay philosophy, attitudes and legislation about suicide. Revel; 1984.

23. Phenomena MJ. Causes of suicides in Russian schools. Moscow; 1914.

24. Florovsky, Vladimir. Suicide of children in Odessa for 10 years. 1903 1913: from materials of odes, of emergency med, pomoschi: experience issled: Soobshch. in a meeting Honey. Islands in Novoros. University 7.05.1914 Odessa; 1915 .

25. Korovin AM. Suicide and vodka consumption in European Russia from 1903 to 1912, the first year. Moscow; 1916.

26. Levitsky I. The Fight against suicide of students: proc. the Senate. Garin and Min. Nar, prosv. Irkutsk; 1911.

27. The most recent reports of the St. Petersburg mayor's office and the police for 1885-1894 (1887-1896). St. Petersburg; 1899.

28. The related activities of the St. Petersburg municipal administration and the Metropolitan police. (1894-1896). Saint-Petersburg.

29. Pasternacki I. A statistical study of suicides in St. Petersburg in 1870 , 1871 and 1872 years. Medical Bulletin. 1873;34(36):38-41.

30. Annex K. Report on the activities of the St. Petersburg municipal administration; 1897.

31. Rechercheable nombre des suicides etdes homicides commis Yong Russie pendant Les Annees 1819 et 1820 pairs H-Th. Herrmann. Memoires de I Academic Imperiale des Sciences de St. Petersbourg. (1832). St Petersburg. 1818;6(1):1-4.

32. Suicide, attempted suicide and accidents among pupils of educational institutions of the Ministry of national Prosveshcheniya / M-Nar. pros. Medical.-San. h. proc. institutions. (1906-1916). Petrograd.

33. Statistical Yearbook of St. Petersburg. The year of the eighth, (1889) Saint-Petersburg; 1888.

34. Military-statistical Yearbook of the army for 1910, 1911 (1911-1913). Saint-Petersburg; 1813.

35. Annals of the Central Statistical Committee of the Ministry of internal Affairs No. 41 "Died violently and suddenly in European Russia in 18881893” / CSK MIA. (1897). Saint-Petersburg.

36. Reports the St. Petersburg mayor. (1873-1893). Saint-Petersburg. 